\title{
Definitely Related to Intervention
}

National Cancer Institute

\section{Source}

National Cancer Institute. Definitely Related to Intervention. NCI Thesaurus. Code C53260.

A characteristic used to qualify the adverse event as certainly related to the medical intervention. According to WHO causality assessment criteria of suspected adverse reactions it is applicable to a clinical event, including laboratory test abnormality, occurring in a plausible time relationship to medical intervention, and which cannot be explained by concurrent disease or other interventions. The response to withdrawal of the medical product (dechallenge) should be clinically plausible. The event must be definitive pharmacologically or phenomenologically, using a satisfactory rechallenge procedure if necessary. 